\title{
Attraction to physical activity of generation Z: A mixed methodological approach
}

\author{
David D. Biber ${ }^{*}$, Daniel R. Czech, Brandonn S. Harris, Bridget F. Melton \\ Health and Kinesiology, College of Health and Human Sciences, Georgia Southern University, Statesboro, USA; \\ *Corresponding Author: david.d.biber@gmail.com
}

Received 19 April 2013; revised 22 May 2013; accepted 30 May 2013

Copyright (C) 2013 David D. Biber et al. This is an open access article distributed under the Creative Commons Attribution License, which permits unrestricted use, distribution, and reproduction in any medium, provided the original work is properly cited.

\begin{abstract}
The prevalence of obesity in Generation Z, which includes individuals born after the year 2000, has tripled that of Generation Xers of 1980 [1]. Rising levels of obesity have been associated with increased physical inactivity (PA) [2]. Attraction to physical activity can be grounded in the Self-Determination Theory (SDT) [3], which defines intrinsic and extrinsic motivation and the roles each type of motivation plays in social and cognitive development. The purpose of the current research was to use a mixed-methodological approach to understand attraction to physical activity of a Generation Z sample via semistructured focus groups and the Children's Attraction to Physical Activity (CAPA) assessment. Based on these results, the secondary purpose was to determine whether significant differences exist between attraction to physical activity and gender within the Generation $Z$ sample. The focus groups revealed two overarching themes: attraction and aversion to physical activity, each with subthemes. The CAPA test revealed significant differences between males and females $(t=$ 2.78, df $=63, p=<0.05$ ), indicating that males (3.39 \pm 0.32$)$ were significantly more attracted to physical activity than females $(3.13 \pm 0.40)$. The clinical relevance is discussed as being future research and program implementation suggestions.
\end{abstract}

Keywords: Generational; Motivation; Physical Activity; Zeds

\section{INTRODUCTION}

A generation refers to a group of people born in the same era, shaped by the same times and influenced by the same social markers [4]. Three generations, X, Y, and $Z$, profoundly influence the world in which we live due to marked social, developmental, and psychological differences. Generation X includes individuals born between the years of 1965 and 1981 [5]. Generation Y (also known as Millennials and Echo Boomers) includes individuals born between 1982 and 1999 [6]. Generation Z (also known as Zeds) includes those individuals born since the year 2000 to the present. Due to the increased use of technology, Generation $\mathrm{Z}$ spends more time indoors, is less physical activity, and more obese compared to previous generations [7].

The majority of Americans agree that a generational divide or gap exists, which is the social phenomenon of differences in values, beliefs, and fashions between people of different age groups [8]. These differences can be explained by the four generational turnings or cycles [9]. The four cycles can be viewed in a pendulum-like nature and, although not predictable, each generation is a factor of its times and a reaction to the previous generation [4].

Due to the increased technology, multiple developed countries and their youth are all influenced by the same events, trends, and developments [4], designating Generation $\mathrm{Y}$ and $\mathrm{Z}$ as global generations. One of the more threatening global markers of the Millennials and Zeds is that of physical inactivity and rising obesity. As of 2008 , $17 \%$ of children ages $6-11$ were obese, which is triple that from Generation X of 1980 [1]. This increasing percentage of obesity, and resulting health problems, could be associated with an overall lack of physical activity (PA).

Children and adolescents aged 6 - 17 need an average of 60 minutes of vigorous PA every day to maintain a healthy weight [2]. Nearly $14 \%$ of adolescents report engaging in no PA and nearly $50 \%$ do not engage in enough physical activity [2]. Physical inactivity in children can be viewed in relation to intrinsic motivation. The main focus of the current study relates to attraction to physical activity and how it contributes to intrinsic motivation. 
The self-determination theory and, more specifically, the cognitive evaluation theory (CET), are crucial in understanding physical activity motivation and attraction [3]. CET is a subcomponent of SDT that focuses on the effects of social contexts on intrinsic motivation, or how factors such as rewards, interpersonal controls, and pleasure impact intrinsic motivation. Intrinsic motivation is related to and helps fulfill basic psychological needs such as competence, autonomy, and enjoyment [10]. Research has found intrinsic motivation to be associated with increased participation in and adherence to a number of tasks, including PA [3,11-13].

Extensive research has been conducted with adolescents and adults, but the research regarding intrinsic motivation as it pertains to physical activity in children is limited. Biddle and Asare have found sedentariness in children to be negatively correlated with mental health [14]. In addition, Biddle, Trish, and Stensel indicate achievement orientation, perceived competence, and intentions to be active as positively correlated [15]. PA has also been found to be related to perceived enjoyment, self-efficacy, competence, control, autonomy, and positive attitude $[16,17]$. Finally, Spray, Wang, Biddle, and Chatzisarantis tested two motivational theories in physical activity with children. Results indicated that children in the autonomous condition reported greater enjoyment, longer adherence, and better performance in physical activity than those in a controlling communication condition [18].

Gender differences in PA participation and motivation have been studied in children. Sallis, Prochaska, and Taylor (2000) found males to engage in more PA than females as they transitioned from childhood to adolescence [19]. Butt, Weinberg, Breckon, and Clayton (2011) found that males are more attracted to PA than females [20]. Males valued fun in regards to PA, while females value social interaction and recognition. Biddle, Whitehead, O'Donovan, and Nevill (2005) found PA to be positively correlated with psychological factors such as enjoyment, perceived competence, and self-efficacy in adolescent females [21].

It is important to understand the PA motives of children as the type and amount of PA one engages in as a child affects the type and amount of PA one engages in as an adult [22]. In addition, being overweight or obese as a child greatly increases the chances one has of being overweight as an adult [23]. Since intrinsic motivation has been associated with adherence to PA, understanding the intrinsic motivations of children could potentially increase their PA, and reduce their likelihood of being obese. Therefore, the purpose of the current research is to use a mixed-methodological approach to examine the attraction to physical activity of a Generation $\mathrm{Z}$ sample. This will be conducted via focus group interviews and the CAPA assessment. Based on these results, the secondary purpose will be to determine whether significant differences exist among physical activity motives between males and females within the Generation $Z$ sample.

\section{METHODS}

\subsection{Participants}

Participants were recruited from elementary schools in the northern Indiana and southern Georgia areas. Participants were divided into four focus groups of seven individuals from the Generation $\mathrm{Z}$ population (ages 10 13). The participants were selected via a purposeful sample. The participants were selected based on age. Sixty five participants completed the CAPA assessment. Participants were contacted via principals and teachers in their respective schools both verbally and through email. Participants were allowed to participate in the study after parental consent and child assent was given.

\subsection{Instrumentation}

\subsubsection{Children's Attraction to Physical Activity (CAPA)}

The Children's Attraction to Physical Activity questionnaire (CAPA) was used to assess overall attraction to physical activity in a Generation Z sample [24,25]. The CAPA consists of 25 items each scored on a four-point scale. A structure alternative format was used to help reduce socially desirable responses [26]. Each item was scored from one to four, with a one indicating low attraction to PA and a four indicating high attraction to PA. The CAPA has been validated with North American children ranging in age from 9 to 12 years, with internal reliability of $0.72[24,25,27]$.

\subsubsection{Focus Group Interviews}

The main method of obtaining information and recording data in a phenomenological study is through the researcher interacting directly with the participant. The was asked the six semi-structured questions and responses were thematized [28]. The researcher indicated motivation to engage in PA to stay in shape, socialize, and mentally relax and aversion based on inexperience and intense. Following the bracketing interview, semitructured focus group interviews were conducted with willing participants and they responded to open-ended questions regarding attraction to PA. The focus groups were of mixed gender with seven participants per group. The sessions consisted of 6 open-ended questions derived from the Children's Attraction to Physical Activity (CAPA) questionnaire. The interview questions were unbiased, non-threatening, and open-ended so as to allow the participants to respond in whatever way they see fit. The interview focused fully on the experience of the 
participant. The qualitative approach of the semistructured focus groups allowed for rich and thick description, which is necessary for qualitative research [29].

\subsection{Procedures}

Following institutional review board approval, initial consent was obtained from the principals and teachers at each school in the northern Indiana and southern Georgia regions. Willing fourth and fifth grade teachers in the northern Indiana region were asked for their class' participation in focus group interviews and the CAPA assessment. Each teacher provided their students with a URL leading to parental consent and student assent forms along with a demographic survey. The consent and assent forms were completed online with electronic signatures required at the bottom of each consent form. Each survey was sent using Qualtrics Mail and Panel system.

After parental consent and child assent was received from an entire classroom, focus group interviews were then conducted with a class in the Indiana school. Focus group interviews consisted of open-ended questions and statements derived from the CAPA. One class of 28 was divided at random into four groups of seven individuals. Each group then sat on the floor in a quiet classroom and told to answer as honestly and openly as possible, and that they could speak until they had fully responded to each question or statement. They were also told that they did not have to answer a question if they didn't want, and could return to the classroom if they felt uncomfortable. Each interview was recorded with both an iPhone and an iPad using Phillips Dictation Recorder for later transcription. After completing the interview, each focus group was allowed to ask any questions and be further debriefed. Each interview lasted for approximately thirty minutes. The CAPA was administered concurrently with the focus group interviews in an electronic and paper and pencil format. Some participants completed the CAPA before the interview while some completed it after. They were instructed to answer each question honestly and regarding their own personal preference. They were reminded that they did not have to complete the assessment and could stop answering at any point. Overall attraction to PA was assessed with a generational perspective along with gender differences.

\subsection{Data Analysis}

\subsubsection{Quantitative Analysis}

Variations in attraction to physical activity among the Generation $\mathrm{Z}$ population were reported by mean and standard deviation on the CAPA. Descriptive statistics such as frequencies and means were calculated for the demographic information of the sample. An independent t-test was run to determine mean attraction to physical activity per participant. The independent t-test was run to assess differences in attraction to physical activity for gender. The independent variable was gender. The dependent variables included the overall CAPA score and the mean average score per participant. Alpha levels were set at $\mathrm{p}<0.05$ with $95 \%$ confidence intervals. SPSS version 17.0 was used to analyze the data.

\subsubsection{Qualitative Analysis}

With qualitative research, the data must be defined with meaning, clarity, and discrimination [30]. The main goals when analyzing the data include: capturing the participant's experience, maintaining the meaning of the text from the interview while maximizing its usefulness, maintaining confidentiality while analyzing data, interpreting the data conservatively and not jumping to conclusions or allowing biases to interfere, and describing the general experience of the participant [31]. These goals were maintained by using a four-step method involving approaching interviews, focusing the data, phenomenological reduction, and releasing meanings [28,30-32]. Triangulation helped minimize bias throughout data collection and analysis and maintain validity [33]. Triangulation included a bracketing interview, peer checking, and expert checking.

\section{RESULTS}

\subsection{Quantitative Results}

The CAPA dataset was analyzed using an independent t-test with an alpha level of 0.05 . Reponses included $\mathrm{N}=$ 38 males and $\mathrm{N}=28$ Females. One female's data was eliminated due to incompletion of the CAPA survey. An independent $\mathrm{t}$-test was conducted to examine whether there was a significant difference in attraction to physical activity between males and females. The mean response for males was $3.39 \pm 0.32$ while the mean response for females was $3.13 \pm 0.40$. The test revealed a statistically significant difference between males and females ( $\mathrm{t}(63)$ $=2.78, p \leq 0.008$, Cohen's $d=0.80$ ). The results of the independent $t$-test indicate that males $(3.39 \pm 0.32)$ were significantly more attracted to physical activity than females $(3.13 \pm 0.40)$. Reliability statistics were run indicating strong internal consistency, with a Cronbach's alpha of 0.88 .

\subsection{Qualitative Results}

The focus group interviews were transcribed and thematized so that attraction to physical activity of a Generation $\mathrm{Z}$ sample could be understood. Three out of the 
four focus groups had to have mentioned a topic with half of the participants discussing that topic for thematization. Male and female themes were then distinguished. The focus group responses were thematized into attraction and aversion to physical activity. Four main themes emerged regarding attraction to physical activity.

\subsection{Generational Themes (Table 1)}

\section{Attraction to Physical Activity}

Being Active and Healthy

The first theme to emerge regarding attraction to physical activity was being active and healthy. This theme emerged mainly in response to "What comes to mind when you think of physical activity". Responses included eating healthy, moving and exerting energy, sweating, stretching, and building muscle.

"Sometimes I just feel the need to burn some energy. Right after I eat or sometimes when I feel kind of hyper I'll go outside and play. I like to play in the afternoon sometimes."

Skill Mastery

Participants also mentioned improving a certain or set of skills as what attracts them to physical activity. This seemed to be a source of motivation for participants.

"You just know that you can always get better more better. So once you get good you can get to better and then play better."

Accomplishment

The third theme to emerge related to beating others, accomplishment, and winning. This was mainly a response to describe their favorite physical activity experience.

"But what makes me want to go is I know that I can beat others on my team."

Social Interaction and Support

The fourth theme to emerge regarding attraction to physical activity involved social interaction with peers, teammates, and friends, and social support from family and friends. These themes emerged mainly in response to there and they'll actually, and they'll like cheering for

Table 1. Generational themes.

\begin{tabular}{lll}
\hline & Generation Z \\
\hline & $\bullet$ & Being Active and Healthy \\
Attraction & $\bullet$ & Skill Mastery \\
& - & Accomplishment \\
& - & Social Interaction and Support \\
& $\bullet$ & Incompetence \\
Aversion & - & Fear of Injury \\
& - & Lack of Social Support \\
\hline
\end{tabular}

me, motivation to engage in physical activity and peer influence on physical activity participation.

"I really just like knowing the fact that my friends are because they're my good friends. And my family will be there too."

\subsection{Aversion to Physical Activity}

Focus groups also provided insight as to aversive factors to physical activity.

\subsubsection{Incompetence}

Aversion to physical activity involved failing related to self-imposed mental pressure to succeed and negative self-talk.

"I tried to do track one time, and I just couldn't do it, and that's not fun for me because if you constantly have in your mind "I can't do it, I can't do it, I can't do it..." then that's because then it's gonna become real and you can't do it. And that's just not gonna be fun to work toward something you can't do."

\subsubsection{Fear of Injury}

When asked to describe least favorite physical activity experiences or motivation to engage in certain in physical activity, participants continually mentioned fears of past injury and the potential to become injured.

"I also don't like jumping on a trampoline. It's not the fact that it gets boring after a while, it's just that one time I fell off, and like really hurt myself. Oh my gosh, that hurt. And then like the next time I got on it I got hurt again, like I kept getting hurt, so I just decided it wasn't that fun anymore."

\subsubsection{Lack of Social Support}

Lack of social support emerged after the focus groups were asked to describe why they are motivated to partake in physical activity and how their friends influence what physical activity they play. Participants seemed to assume their peers would judge them based on talent, mistakes or errors, leading to less attraction.

"You might think, they might tease me because I'm not so good and I'm just on a new team."

\subsection{Gender Specific Themes (Table 2)}

As previously discussed, males were significantly more attracted to physical activity as females based on the CAPA assessment. Differences also emerged in regard to what was said during the semi-structured focus groups in regard to attraction and aversion to physical activity. Gender was thematized based on the questions and statements asked to the focus groups, resulting in varying themes. 
Table 2. Gender themes.

\begin{tabular}{|c|c|c|}
\hline & Males & Females \\
\hline Attraction & $\begin{array}{ll}\text { - } & \text { Improving } \\
\text { - } & \text { Skills/Advancement } \\
\text { - } & \text { Incentives } \\
\text { - } & \text { Social Support }\end{array}$ & $\begin{array}{l}\text { - Winning and } \\
\text { Accomplishment } \\
\text { - Social Support } \\
\text { - Preparation for } \\
\text { Competition }\end{array}$ \\
\hline Aversion & $\begin{array}{ll}\text { - } & \text { Fear of Injury } \\
\text { - } & \text { Pressure to Succeed }\end{array}$ & $\begin{array}{ll}\text { - } & \text { Fear of Injury } \\
\text { - } & \text { Incompetence } \\
\text { - } & \text { Boredom } \\
\text { - Negative Social } \\
\text { Influence }\end{array}$ \\
\hline
\end{tabular}

\subsubsection{Male Attraction Themes}

When asked to describe their favorite physical activity experience, the males emphasized having participated in the activity for many years, having the chance to perfect a set of skills, expending energy, incentives, and social support.

\subsubsection{Improving Skills/Advancement}

Males were attracted to physical activity, predominantly sports, in which they had the opportunity to improve upon a set of skills or tasks.

"You get better, better and eventually perfect things. And make new friends and have a good time and fun stuff."

\subsubsection{Expending Energy}

Males seemed attracted to physical exertion in relation to physical activity. They liked getting sweaty, dirty, and feeling their body working.

"I like track and basketball. I like them because you're constantly running... in basketball and track you can run long distance and short distance."

\subsubsection{Incentives}

"In sports a lot of times if I play, I got to play for a long time, then for like 5 to 10 minutes. So I'm tired and then my mom lets me play computers which is nice. So it's like if you do something good for yourself, and then you get something that's like mentally fun."

\subsubsection{Social Interaction/Support}

Participants seemed to enjoy participating in physical activity that their family or relatives had participated in.

"I-I, well my... I was going to quit soccer two years ago but my mom and Alex, one of my friends, both encouraged me. So I wouldn't quit this game."

\subsection{Males Aversion Themes}

\subsubsection{Fear of Injury}

Nearly all of the male participants expressed disliking past experiences or future possibilities of getting injured or hurt in physical activity.

"I also don't like fencing. It was... first it was fun, until they told me about, like the sticks that you jab with... how they're sharp at the end. I was in a duel and it fell on my head."

\subsubsection{Pressure to Succeed}

The pressure to succeed at a task or activity seemed to be perceived negatively by the male participants. They strongly disliked this pressure, often to the point of ceasing to participate in the physical activity.

"For football, I also don't like when you, it's when... it's kind of, well, it's a lot of pressure for me, when someone throws the ball, you're supposed to be expected to catch it like all the time and, if you get tackled you drop it... It kind of worries me, and when I get worried it's harder for me to succeed. So, it kind of just makes me feel like I'm gonna drop it. And so, like she said, mentally and then physically."

\subsection{Female Attraction Themes}

\subsubsection{Winning and Accomplishment}

"One time when I was swimming I was against my friend who's in my class there... and we were doing the butterfly, and that's my weakest stroke. And it was like her best stroke. It was one of my weakest strokes, [LAUGH] and I was so nervous that I was gonna lose, and so you're not allowed to touch the ground. And I had to start doing the breast stroke with my feet, and I managed to keep on doing the butterfly the way. I thought I was last and when I got out of the water... It turned out I was first place."

\subsubsection{Social Support}

"I really just like knowing the fact that my friends are there and they'll actually, and they'll like cheering for me, because they're my good friends. And, my family will be there, too. And all that."

\subsubsection{Preparation for Competition}

"Whenever I start to cheerleading practice I think about what's gonna come up next at the very next competition. Because it's competitive cheerleading, I, I have to... so, if I want to do good and have fun there, I'm gonna have to do this first."

\subsection{Female Aversion Themes}

\subsubsection{Fear of Injury}

"I also don't like jumping on a trampoline. It's not the fact that it gets boring after a while, it's just that one time I fell off, and like really hurt myself. Oh, gosh, that hurt. And then-and then like-and then like the next time I got on it I got hurt again, like I kept getting hurt, so I just 
decided it wasn't that fun anymore."

\subsubsection{Incompetence}

"I feel so pushed down, but it's kind of like, okay, so like imagine like this little tube thing, and you start at 100 percent. You can do this. And then you start losing, you down... you go down to about a 95 and... And you keep going down. And then once you get to about a zero you're just, "I can't do this anymore. And you feel so down. You're just done with it. It feels... it doesn't feel very good."

\subsubsection{Boredom}

"Jumping on the trampoline. Because I can't... all I can do is jump up and down, and I can't do any tricks. So, it's not my favorite. It gets a little boring."

\subsubsection{Negative Social Influence}

"I didn't really notice this until way afterwards... sometimes like me and my group of friends, sometimes one of us doesn't like the sport, and then like halfway through when we're done with gym class, until we're done with gym class, all of sudden one of us like won't like the sport, and then will go on to like none of us like the sport.

\section{DISCUSSION}

The purpose of this study was to examine attraction to physical activity in a Generation $Z$ sample. Participants felt attracted to physical activity where they could be active and healthy. They knew they were being healthy by exercising, exerting energy, and enhancing muscular strength and endurance. Previous research indicates that children in the sampling years derive enjoyment from movement sensations [34]. Children enjoy physical activity in a positive learning environment where they feel confident and competent [35]. This is supported by the SDT, which emphasizes competence and autonomy as important determinants of intrinsic motivation to certain behavior [3]. Youth who participate in unstructured physical activity find more enjoyment and intrinsic motivation from participation [36].

With regard to skill mastery, participants mentioned wanting to get better, learn certain skills they had been practicing, and advancing to higher levels of skill. Scanlan and Lewthwaite (1986) measured sport enjoyment experienced by 9 to 14 years old wrestlers. They found that boys who perceived their wrestling ability as greater enjoyed their sport more than those with lower perceptions [37]. Improving skills can be linked to overall competence as a source of enjoyment in physical activity. In a study by McCarthy and Jones (2007), both young and old children derived enjoyment from mastery processes in physical activity [34]. As youth begin to specialize in sport, competence and mastery may become greater sources of enjoyment [38]. Competence is part of a triad of necessities of the self-determination theory that contribute to intrinsic motivation to engage in and enjoyment in physical activity [3].

Participants' emphasis on "winning," "beating others" and being "victorious is contradictory to a meta-analysis in which children described sport participation as more enjoyable when not forced to compete and win [39]. However, the present findings are supported by McCarthy \& Jones (2007), who found that children enjoyed being superior in sport, defined as "being better than peers at a sport or receiving recognition for a performance" [34]. Generation $\mathrm{Z}$ expects immediate results and rewards [4]. Their need for accomplishment supports this view of Generation $\mathrm{Z}$ as outcome oriented.

Finally, participants were attracted to physical activity in which they were with supportive friends. Young and older children enjoy developing friendships, social support, and encouragement [34]. The SDT emphasizes feelings of relatedness as important intrinsic motivators for physical activity adherence [3]. Children age eleven to fourteen emphasize peer comparison as sources of attraction to physical activity [40]. A meta-analysis regarding motives to engage in physical activity and sport found that support from family and significant others, developing social networks, and shared experiences were all described as attractive and enjoyable aspects of participation from youth through old age [39]. Generation Z is a global generation that yearns for social support from peers more so than any previous generation [4].

Participants also described certain aversive factors of physical activity participation. The participants of the present study found past failures and the inability to successful as motives to avoid certain physical activity. In a study by Ntoumanis (2001), competence was found to be the strongest contributor to self-determination in physical activity in 14 - 16 year olds [41]. Young girls reported disliking physical activity in which they felt incompetent [42]. Competence is a major contributing factor in determining intrinsic motivation to engage and adhere to exercise and sport activity and lack of competence hinders such participation $[3,34]$. From a generational standpoint, Zeds are the most competent generation regarding technology and learning yet struggle in and fear some basic activities like PA and sport [4].

Nearly all of the participants mentioned certain injuries, potential injuries, and harmful peers as reasons for not wanting to participate in physical activity. Generationally, the Zeds lack freedom and are the most protected by their parents in comparison to previous generations [4]. The caution showed by parents seems to be influencing their children, enhancing their fears regarding physical activity. Warnings from the media and other 
experts seem to be compounding the fears of parents for dangerous PA activities [43]. The family size and number of children per family have also contributed to overprotecting children and parents' perceptions of danger. With fewer children, parents aim to protect their children from any and all dangers or failures [6].

Lack of social support was also expressed as a reason for not participating in physical activity. Relatedness, a component of enjoyment, intrinsic motivation, and the SDT, has been found to be directly associated with physical activity enjoyment $[3,44]$. Children have been found to derive competence from social comparison and support with peers, indicating that a lack of social support or competence could hinder intrinsic motivation to engage in physical activity $[45,46]$. As a global generation, the Zeds are experiencing more bullying, peer pressure, and negative influence than any previous generation because of their constant connection with each other [4].

In addition to generational themes, gender-specific themes emerged from the present study. The CAPA assessment indicated that males were more attracted to physical activity than females. Consistent with previous research, that males valued fun as a motivation to engage in PA in comparison to females [20]. Sallis, Prochaska, and Taylor [19] found males to be more physically active than females throughout the transition from childhood to adolescence [19].

Males emphasized expending energy, improving a set of skills, and incentive-based participation. Males have been found to be more attracted to physical activity that allows them to exert energy and get out of breath [20]. In a study by Brustad (1993), children tended to rank fun and improving or learning new skills as the top reasons to participate in sport [24]. However, this ranking is consistent across gender, whereas males emphasized skill improvement but this theme wasn't as evident for females. The fact that winning emerged as a theme for females and not males in the present study is contradictory to previous gender research in physical activity. Previous research has found that males tend to enjoy competition, demonstrating ability and victory [47-49]. Teenage girls described learning new skills, development of new social networks, and improved fitness and self-esteem as motivators to be physically active [50]. Winning has been cited as one of the least important factors in sport and physical activity participation in previous research [51]. The females' emphasis on winning could be due to socialization or parental/peer influence [52].

Aversion to physical activity also emerged from the present study. The males indicated feeling pressure to succeed from parents, peers, and from their self. Research supports the notion that pressure to succeed or win in sport is positively related to stress and inversely related to enjoyment $[53,54]$. Youth often feel excessive pressure to win, leading to less positive sport experiences and attrition [55]. Parents' criticism and expectations to succeed have also been found to be related to burnout [56]. Females disliked feelings of incompetence, boredom, and negative social influence. Adolescent girls with higher perceived competence have been found to be more physically active [57]. Females are most attracted to physical activity for the social interaction and peer recognition [20]. Negative feedback has been found to reduce attraction to physical activity [58]. In a study by $\mathrm{Vu}$, Murrie, Gonzalez, and Jobe (2006), when asked what motivated them to be active, 12 years old girls responded with parental encouragement [59]. Adolescent females reported being teased at a higher rate than males and having lower sport participation than males [60]. The higher occurrence of teasing towards females has been found to decrease enjoyment and participation in physical activity [59]. This study supports the notion that feelings of incompetence and negative social influence can reduce the likelihood of engaging in physical activity. Generation $\mathrm{Z}$ will have the largest transition from adolescence to the workforce, spending their young adult years in a time of economic and social renewal [4]. That being said, the prevalence of obesity could greatly impact their ability to flourish.

\section{Implications for Practice, Limitations, and Future Research}

The present study emphasizes the importance of autonomy, competence, relatedness and enjoyment in this Generation $\mathrm{Z}$ sample. With increasing rates of physical inactivity and obesity finding PA that children enjoy could be helpful in deterring further increases $[1,23]$. School-related PA programs could emphasize confidence, competence, and social support. By understanding factors related to aversion to physical activity, programs could attempt to minimize negative social influence, failure, and injury so as to increase enjoyment. In-school and after-school programs could take gender differences into account when planning and implementing PA. Programs could combine both male and female-oriented activities, or try to include gender neutral activities that remain clear of gender stereotypes. Sport sampling rather than sport specialization could be emphasized, seeing as how sampling contributes to competence and enjoyment [36, $61,62]$.

This study was conducted with minimal external bias, but as with all research, certain limitations were inevitable. Half of the participants completed a paper and pencil CAPA, while the second half completed the CAPA survey via email. This could have contributed to completion, priming of responses, attention to questions, or pressure to answer honestly. In addition, the focus groups were completed in Indiana and not in Georgia, although 
CAPA surveys were conducted from both states. Certain responses may have been due to social influence or pressure. The focus groups were also mixed-gender, potentially making some participants feel uneasy about answering truthfully or openly. Future research could examine attraction to physical activity from a longitudinal perspective to determine whether intrinsic motivation to engage in physical activity fluctuates along the motivational continuum. Separate gender focus groups could also be conducted with separate gender groups to help remove pressure to answer with socially desirable. Research could also examine attraction specifically to sport. Recent research indicates that a high amount of children are quitting and experiencing burnout in youth sport [63]. Understanding why children do and do not want to participate in sport could help coaches and parents create a more enjoyable sport experience. Keeping these results in mind with implementation, researching, parenting or coaching can be advantageous in enhancing youth physical activity and sport enjoyment.

\section{REFERENCES}

[1] Ogden, C.L., Curtin, L.R., Lamb, M.M. and Flegal, K.M. (2010) Prevalence of high body mass index in US children and adolescents. Journal of the American Medical Association, 303, 242-249.

[2] CDC (2011) Adolescent and school health: Childhood obesity facts, 2011. US Department of Health and Human Services, Atlanta.

[3] Deci, E.L. and Ryan, R.M. (1985) Intrinsic motivation and self-determination in human behavior. Plenum Press, New York.

[4] McCrindle, M. and Wolfinger, E. (2008) The ABC of $X Y Z$ : Understanding the global generations. University of New South Wales Press Ltd., Sydney.

[5] Noble, S.M., Haytko, D.L. and Phillips, J. (2009) What drives college-age generation y consumers? Journal of Business Research, 62, 617-628. doi:10.1016/j.jbusres.2008.01.020

[6] Engebretson, J. (2004) Odd generation out. American Demographics, 26, 14-17.

[7] Smith, A.M., Lopez-Jimenez, F., McMahon, M.M., Thomas, R.J., Wellik, M.A., Jensen, M.D., et al. (2005) Action on obesity: Report of a Mayo Clinic national summit. Mayo Clinic Proceedings, 80, 527-532.

[8] Grose, M. (2005) XYZ. The new rules of generational warfare. Random House Publishing, Sydney.

[9] Strauss, W. and Howe, N. (1997) The fourth turning: An American prophecy-What the cycles of history tell us about America's next rendezvous with destiny. Broadway, Great Falls.

[10] Frederick-Recascino, C.M. (2002) Self-determination theory and participation motivation research in the sport and exercise domain. In Deci, E.L., Ryan, R.M., Deci, E.L. and Ryan, R.M., Eds., Handbook of Self-Determination
Research. University of Rochester Press, Rochester, 277 294.

[11] Bartlett, J.D., Close, G.L., Maclaren, D.M., Gregson, W., Drust, B. and Morton, J.P. (2011) High-intensity interval running is perceived to be more enjoyable than moderate-intensity continuous exercise: Implications for exercise adherence. Journal of Sports Sciences, 29, 547-553. doi:10.1080/02640414.2010.545427

[12] Ebben, W. and Brudzynski, L. (2008) Motivations and barriers to exercise among college students. Journal of Exercise Physiology Online, 11, 1-11.

[13] Fleig, L., Lippke, S., Pomp, S. and Schwarzer, R. (2011) Exercise maintenance after rehabilitation: How experience can make a difference. Psychology of Sport \& Exercise, 12, 293-299. doi:10.1016/j.psychsport.2011.01.003

[14] Biddle, S.J.H. and Asare, M. (2011) Physical activity and mental health in children and adolescents: A review of reviews. British Journal of Sports Medicine, 45, 886-895. doi:10.1136/bjsports-2011-090185

[15] Biddle, S.J.H., Trish, G. and Stensel, D.J. (2004) Healthenhancing physical activity and sedentary behaviour in children and adolescents. Journal of Sports Sciences, 22, 679-701. doi:10.1080/02640410410001712412

[16] Biddle, S.J.H., Sallis, J.F. and Cavill, N., Eds. (1998) Young and active? Young people and health-enhancing physical activity: Evidence and implications. Health Education Authority, London.

[17] Cavill, N., Biddle, S.J.H. and Sallis, J.F. (2001) Healthenhancing physical activity for young people: Statement of the United Kingdom Expert Consensus Conference. Pediatric Exercise Science, 13, 12-25.

[18] Spray, C.M., Wang, C.K.J., Biddle, S.J.H. and Chatzisarantis, N.L.D. (2006) Understanding motivation in sport: An experimental test of achievement goal and self determination theories. European Journal of Sport Science, $\mathbf{6}$, 43-51. doi:10.1080/17461390500422879

[19] Sallis, J.F., Prochaska, J.J. and Taylor, W.C. (2000) A review of correlates of physical activity of children and adolescents. Medicine in Science and Sports and Exercise, 32, 963-975. doi:10.1097/00005768-200005000-00014

[20] Butt, J., Weinberg, R.S., Breckon, J.D. and Claytor, R.P. (2011) Adolescent physical activity participation and motivational determinants across gender, age, and race. Journal of Physical Activity and Health, 8, 1074-1083.

[21] Biddle, S.J.H., Whitehead, S.H., O'Donovan, T.M. and Nevill, M.E. (2005) Correlates of participation in physical activity for adolescent girls: A systematic review of recent literature, Journal of Physical Activity and Health, 2, 421-432.

[22] O'Brien Cousins, S. (1998) Exercise, aging and health. Taylor \& Francis, Philadelphia.

[23] Simons-Morton, D.G., Obarzanek, E. and Cutler, J.A. (2006) Obesity research-Limitations of methods, measurements, and medications. The Journal of the American Medical Association, 295, 826-828. doi:10.1001/jama.295.7.826

[24] Brustad, R.J. (1993) Who will go out and play? Parental 
and psychological influences on children's attraction to physical activity. Human Kinetics Publishers, Inc., 5, 210223.

[25] Brustad, R.J. (1996) Attraction to physical activity in urban school children: Parental socialization and gender influences. Research Quarterly for Exercise and Sport, 67, 316-323. doi:10.1080/02701367.1996.10607959

[26] Harter, S. (1982) The perceived competence scale for children. Child Development, 53, 87-97. doi: $10.2307 / 1129640$

[27] Rose, E., Larkin, D., Hands, B., Howard, B. and Parker, H. (2009) Evidence for the validity of the children's attraction to physical activity questionnaire (CAPA) with young children. Journal of Science and Medicine in Sport, 12, 573-578. doi:10.1016/j.jsams.2009.05.009

[28] Czech, D.C., Wrisberg, C.A. and Fisher, L.A. (2004) The experience of Christian prayer in sport. Journal of Psychology and Christianity, 1, 3-11.

[29] Boyd, C.O. (1993) Qualitative approaches in nursing research. Phenomenology: The method. NLN Publications, 19, 99-132.

[30] Henderson, D. (1992) The experience of supervision: A phenomenological investigation. Unpublished Doctoral Dissertation, University of Tennessee, Knoxville.

[31] Hawthorne, M.C. (1988) The human experience of reparation: A phenomenological study. Unpublished Doctoral Dissertation, University of Tennessee, Knoxville.

[32] Patton, M.Q. (2002) Qualitative research and evaluation methods. Sage Publications, Newbury Park.

[33] Polkinghorne, D.E. (1989) Phenomenological research methods. In: Valle, R.S. and Halling, S., Eds., ExistentialPhenorrumological Perspectivesin Psychology. Plenum Press, New York. doi:10.1007/978-1-4615-6989-3 3

[34] McCarthy, P.J. and Jones, M.V. (2007) A qualitative study of sport enjoyment in the sampling years. The Sport Psychologist, 21, 400-416.

[35] Wallhead, T.L. and Buckworth, J. (2004) The role of physical education in the promotion of youth physical activity. Quest, 56, 285-301. doi:10.1080/00336297.2004.10491827

[36] Coté, J. and Fraser-Thomas, J. (2007) Youth involvement in sport. In: Crocker, P.R.E., Ed., Introduction to Sport Psychology, A Canadian Perspective, Pearson Prentice Hall, Toronto, 266-294.

[37] Scanlan, T.K. and Lewthwaite, R. (1986) Social psychological aspects of competition for male youth sport participants: IV. Predictors of enjoyment. Journal of Sport Psychology, 8, 25-35.

[38] MacPhail, A., Gorely, T. and Kirk, D. (2003) Young people's socialization into sport: A case study of an athletics club. Sport, Education and Society, 8, 251-267. doi:10.1080/13573320309251

[39] Allender, S., Coburn, G. and Foster, C. (2006) Understanding participation in sport and physical activity among children and adults: A review of qualitative studies. Health Education Research, 21, 826-835. doi:10.1093/her/cyl063
[40] Horn, T.S. and Weiss, M.R. (1991) A developmental analysis of children's self-ability judgments in the physical domain. Pediatric Exercise Science, 3, 310-326.

[41] Ntoumanis, N. (2001) A self-determination approach to the understanding of motivation in physical education. British Journal of Educational Psychology, 71, 225-242. $\underline{\text { doi: } 10.1348 / 000709901158497}$

[42] Davison, K.K., Schmalz, D.L. and Downs, D.S. (2010) Hop, skip...no! Explaining adolescent girls' disinclinetion for physical activity. Annals of Behavioral Medicine, 39, 290-302. doi:10.1007/s12160-010-9180-x

[43] Cotton Wool Kids, The Daily Telegraph, 17 May 2008.

[44] Cox, A.E., Smith, A.L. and Williams, L. (2008) Change in physical education motivation and physical activity behavior during middle school. Journal of Adolescent Health, 43, 506-513. doi:10.1016/j.jadohealth.2008.04.020

[45] Horn, T.S. and Harris, A. (2002) Perceived competence in young athletes: Research findings and recommendations for coaches and parents. In: Smoll, F.L. and Smith, R.E., Eds., Children and Youth in Sport: A Biopsychosocial Perspective. 2nd Edition, Kendall-Hunt, Dubuque, 435464.

[46] Allen, J.B. (2003) Social motivation in youth sport. Journal of Sport and Exercise Psychology, 25, 551-567.

[47] Finkenberg, M.E. (1991) Sex and ethnicity as factors for participation in physical activity. International Journal of Physical Education, 28, 23-26.

[48] Gill, D.L. (1988) Gender differences in competitive orientation and sport participation. International Journal of Sport Psychology, 19, 145-159.

[49] Koivula, N. (1999) Sport participation: Differences in motivation and actual participation due to gender typing. Journal of Sport Behavior, 22, 360-380.

[50] Flintoff, A. and Scraton, S. (2001) Stepping into active leisure? Young women's perceptions of active lifestyles and their experiences of school physical education. Sport, Education, and Society, 6, 5-21.

[51] Wankel, L.M. and Kreisel, P.S.J. (1985) Factors underlying enjoyment of youth sports: Sport and age group comparisons. Journal of Sport Psychology, 7, 51-64.

[52] Eccles, J.S. and Harold, R.D. (1991) Gender differences in sport involvement: Applying the Eccle's expectancy value model. Journal of Applied Sport Psychology, 3, 7-35. doi:10.1080/10413209108406432

[53] Hall, H.K. and Kerr, A.W. (1997) Motivational antecedents of precompetitive anxiety in youth sport. The Sport Psychologist, 11, 24-42.

[54] Scanlan, T.K. and Passer, M.W. (1979) Sources of competitive stress in young female athletes. Journal of Sport Psychology, 1, 151-159.

[55] Wankel, L.M. and Mummery, W.K. (1990) The psychological and social benefits of sport and physical activity. Journal of Leisure Research, 22, 167-182.

[56] Baker, J. and Robertson-Wilson, J. (2003) On the risks of early specialization in sport. Physical and Health Education Journal, 69, 4-8. 
[57] Fairclough, S., Hilland, T., Stratton, G. and Ridgers, N. (2012) Am I able? Is it worth it? Adolescent girls' motivational predispositions to school physical education: Associations with health-enhancing physical activity. European Physical Education Review, 18, 147-158. doi:10.1177/1356336X12440025

[58] Viciana, J., Cervello, E.M. and Ramirez-Lechuga, J. (2007) Effect of manipulating positive and negative feedback on goal orientations, perceived motivational climate, satisfaction, task choice, perception of ability, and attitude toward physical education lessons. Perceptual and Motor Skills, 105, 67-82. doi:10.2466/pms.105.1.67-82

[59] Vu, M.B., Murrie, D., Gonzalez, V. and Jobe, J.B. (2006) Listening to girls and boys talk about girls' physical activity behaviors. Health Education Behavior, 33, 81-96.

$$
\text { doi:10.1177/1090198105282443 }
$$

[60] Slater, A. and Tiggemann, M. (2011) Gender differences in adolescent sport participation, teasing, self-objectification and body image concerns. Journal of Adolescence, 34, 455-463. doi:10.1016/j.adolescence.2010.06.007

[61] Côté, J. and Hay, J. (2002) Children's involvement in sport: A developmental perspective. In: Silva, J.M. and Stevens, D.E., Eds., Psychological Foundations of Sport, Allyn \& Bacon, Boston, 484-502.

[62] Kirk, D. (2005) Physical education, youth sport and lifelong participation: The importance of early learning experiences. European Physical Education Review, 11, 239255. doi:10.1177/1356336X05056649

[63] Rotella, R.J., Hanson, T. and Coop, R.H. (1991) Burnout in youth sports. The Elementary School Journal, 91, 421428. 